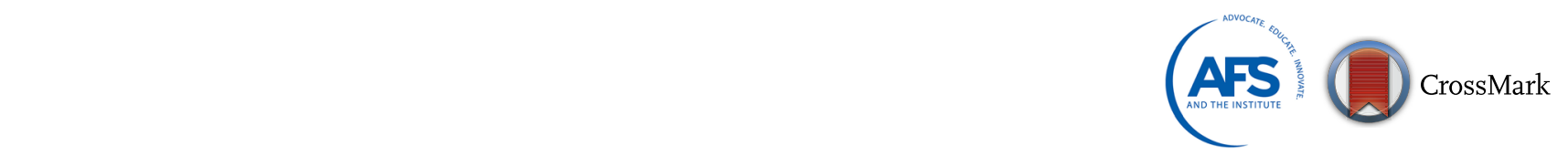

\title{
CORRECTION TO: EFFECTS OF PROCESS RELATED VARIATIONS ON FILLABILITY SIMULATION OF THIN-WALLED IN718 STRUCTURES
}

\author{
Mohsin Raza $(\mathbb{1}$ \\ School of Innovation, Design and Engineering, Mälardalen University, Eskilstuna, Sweden \\ TPC Components AB, Hallstahammar, Sweden \\ Roger Svenningsson \\ Swerea SWECAST AB, Jönköping, Sweden \\ Mark Irwin \\ TPC Components AB, Hallstahammar, Sweden \\ Björn Fagerström \\ School of Innovation, Design and Engineering, Mälardalen University, Eskilstuna, Sweden
}

\section{Anders E. W. Jarfors}

Materials and Manufacturing, School of Engineering, Jönköping University, Jönköping, Sweden

Copyright $\left({ }^{\circ} 2018\right.$ American Foundry Society

https://doi.org/10.1007/s40962-018-0223-6

\section{Correction to: \\ International Journal of Metalcasting https://doi.org/10.1007/s40962-017-0189-9}

The following are errors in the original article. All are corrected as reflected here:

The spelling of fillability is incorrect.

Björn Fagerström's family name is misspelled.
In Fig. 2c, the density of IN718 should have been stated in $\mathrm{kg} / \mathrm{cm}^{3}$. Following is the corrected figure:

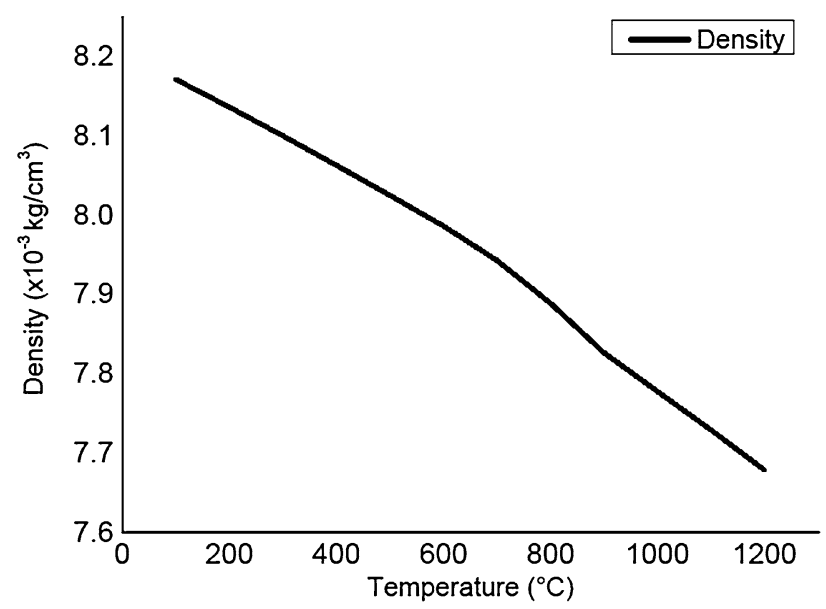

